\title{
Lobbying sways NIH grants
}

\section{Pressure on lawmakers from patient-advocacy groups has shaped agency spending on rare-disease research.}

\section{BY SARA REARDON}

A dvocates for patients with rare diseases spend millions of dollars lobbying the US Congress each year - and it is money well spent, an economic analysis has found. Between 1998 and 2008, such efforts helped to increase new funding for raredisease programmes by $3-15 \%$ each year at the US National Institutes of Health (NIH), according to a report to be published in Management Science (D. Hegde and B. N. Sampat Mgmt Sci. http://doi.org/fzs2vx; 2014).

The effect of this growth on the NIH's total budget (US $\$ 30$ billion in fiscal year 2014) is small; targeted grants accounted for just $10-20 \%$ of the agency's annual grant-making during the study period. But the analysis highlights the fine line that the NIH must tread when choosing diseases to prioritize: maintaining the peer-review process by which it awards grants, but not ignoring the wishes of the lawmakers who control its budget.

Congress curbed the power of lobbyists through a 2010 ban on setting aside money in bills for specific projects - known as earmarks. But lobby groups have shifted strategies. They seek to steer funds using 'soft' earmarks: language in spending bills that encourages or urges an agency to perform some action, such as funding Alzheimer's research, rather than setting aside funds for it (see 'Research rewards').

When economists Deepak Hegde of New York University and Bhaven Sampat of Columbia University in New York City examined the text of congressional reports on the NIH budget for mentions of 955 rare diseases, they found an average of 84 soft earmarks a year for these conditions. The true impact of lobbying on the NIH budget is likely to be even larger than their estimates, they say, because the study examines just a small slice of the agency's research portfolio that does not include diseases such as cancer.

Rachel Best, a sociologist at the University of Michigan in Ann Arbor, says that lobbying provides a way for taxpayers to communicate their priorities to the NIH - and it pays. She analysed funding for 53 diseases over the course of 19 years and found that each $\$ 1,000$ spent on lobbying for a condition correlated with a $\$ 25,000$ increase in funding the following year

\section{RESEARCH REWARDS}

Lobbying by patient-advocacy groups is linked to a rise in 'earmarks' in bills funding rare-disease research at the US National Institutes of Health.

$$
160
$$

Earmarks linked to lobbying - Total earmarks

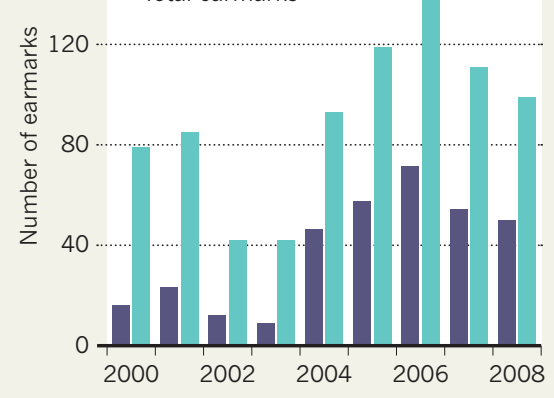

(R. Best Am. Sociol. Rev. 77, 780-803; 2012).

This could be problematic if it starts to skew funding towards research that has little scientific merit or comparatively small public-health benefit, Best adds. She notes that the diseases that affect the most people do not necessarily get the strongest advocacy: she has found that illnesses that primarily affect women and minorities, and stigmatized conditions such as sexually transmitted diseases, tend to receive less lobbying support than other conditions.

Jeremy Berg, a biochemist at the University of Pittsburgh in Pennsylvania and a former director of the National Institute of General Medical Sciences, says that he is neither surprised nor concerned by the findings. If Congress uses a soft earmark to encourage research on a particular topic, he says, "it's something NIH takes seriously" - but does not feel compelled to act on. "In my experience, it's not regarded as a command, but input into what to do."

And Pierre Azoulay, an economist at the Massachusetts Institute of Technology in Cambridge, says that it would be interesting to determine whether targeted grant programmes for specific diseases chosen by the NIH yield better results than grants proposed by individual researchers. "To know whether to be exercised about this, we should look at how scientifically fruitful those different grants are," he says. Hegde says that his group is currently doing just this for all NIH research funding. - 